\title{
ANALYSIS OF THE SCIENTIFIC PRODUCTIVITY AND TECHNICAL EFFICIENCY OF CHILEAN UNIVERSITIES
}

\section{Cristian Colther ${ }^{1}$; Pedro Piffaut ${ }^{2}$; Alba Montecinos ${ }^{3}$}

\begin{abstract}
This research analyzes the scientific production of Chilean universities for the period 2013-2017 using a balanced panel data. The methodology uses an aggregate production function of the Cobb-Douglas type solved by means of a fixed effects panel data model, a Stochastic Frontier Analysis (SFA). The main results show that the models are equivalent and complementary in their analysis -They quantify the impact of financial resources and advanced human capital. The fixed effects model shows that the Chilean university system experiences increasing returns to scale, and the SFA model showed important efficiency gaps among universities. These results are relevant, since the models allow the follow-up and monitoring of public investment, of hiring programs by HEIs, and finally, the adequacy of public policies towards Science and Technology.
\end{abstract}

Key concepts: Scientific productivity; Cobb-Douglas production function; Stochastic Frontier Analysis; technical efficiency; academic research; higher education.

\section{ANÁLISIS DE LA PRODUCTIVIDAD CIENTÍFICA Y LA EFICIENCIA TÉCNICA DE LAS UNIVERSIDADES CHILENAS}

\section{RESUMEN}

Esta investigación analiza la producción científica de las universidades chilenas para el período 2013-2017 utilizando un panel de datos balanceados. La metodología utiliza una función de producción agregada del tipo Cobb-Douglas resuelto por medio de un modelo de datos de panel de efectos fijos un Análisis de Frontera Estocástica (AFE). Los principales resultados muestran que los modelos son equivalentes y complementarios en su análisis y cuantifican el impacto de los recursos financieros y capital humano avanzado. El modelo de efectos fijos muestra que el sistema universitario chileno experimenta rendimientos crecientes de escala, y el modelo SFA mostró importantes brechas de eficiencia entre universidades. Estos resultados son relevantes, ya que los modelos permiten el seguimiento, monitoreo de la inversión pública, de los programas de contratación por parte de las Instituciones de Educación Superior-HEI, y finalmente, de la adecuación de las políticas públicas hacia la Ciencia y la Tecnología.

Conceptos clave: Productividad científica, función de producción Cobb-Douglas, análisis de fronteras estocásticas, eficiencia técnica, investigación académica, enseñanza superior

1 Universidad Austral de Chile, Valdivia, Chile. Contacto: cristian.colther@uach.cl

2 Columbia University, Nueva York, Estados Unidos. Contacto: pnv2102@caa.columbia.edu

3 Universidad Austral de Chile, Valdivia, Chile. Contacto: albamontecinos@uach.cl 


\section{Introduction}

The production of scientific literature has increased significantly in recent decades. This, as a result of the role that various studies assign to scientific progress, technology and investment in human capital in the economic development of countries; all of them understood as relevant factors to the growth of the economies (Fernandez-Cano, Torralbo, \& Vallejo, 2004; Wong, 2019; Barro, 1990, 2001; Erfanian $\&$ B. Ferreira Neto, 2017; Gemmell, 2010; Mueller, 2016, Solarin \& Yen, 2016).

In this context, universities play a fundamental role in producing scientific research. This is generated by the advanced human capital that is put to work, which is continuously formed in these institutions (Scott, 2006). However, it can be seen that universities have differences regarding their ability to produce scientific research. Mainly for the role played by the financial resources that universities use in their management and the availability of academics with the capability to create scientific literature.

The estimation of scientific productivity is a subject of considerable interest. It can help understand the factors that can affect the production of scientific literature and the degree of efficiency in using resources available for research. In this aspect, bibliometric studies can only provide an overview of an educational institution's capability to produce scientific literature in terms of quantity, quality, and impact of the knowledge generated. However, they do not take into account the factors that contribute to scientific literature, through the analysis of the available resources at universities.

This research analyzes the scientific production of Chilean universities for the period 2013-2017. Data panel and two approaches were used to estimate the productivity of universities; a growth model that considers an aggregate production function of the Cobb-Douglas type and a Stochastic Frontier Analysis (SFA). The main contribution of this research is related to the estimation of productivity using a relatively new methodology, SFA, providing the possibility of comparing its results with traditional estimation methods used in previous works. 
The document is developed as follows. Section 2 presents a brief review of the literature that has addressed this issue on a general scope and particularly in the Chilean case. Section 3 shows the methodology followed in the study and the source of information used. Section 4 presents the main results derived from the investigation. Section 5 presents the main conclusions and final comments.

\section{Literature review}

Scientific productivity occupies a place of importance in a society dominated by the value of knowledge, making university research a key element in its development (Castro-Ceacero \& Ion, 2018).

Studies on scientific productivity traditionally address various types of measures, including the number of publications and the number of citations or impact indices. (Wong, 2019). However, these studies only consider the information concerning the quantity and quality of scientific literature production. Still, they do not allow evaluating the degree of efficiency in using the available resources of the organizations to produce scientific literature.

In economics, it is customary to use aggregate production function models to study the factors that can determine economic growth (Acemoglu, 2012). One of the simplest and most widely used is the Cobb-Douglas model, which relates two or more variables or inputs, estimating the contribution of each of them in explaining the change or growth of the dependent variable (Cobb \& Douglas, 1928; Douglas, 1976). Some studies have explored the factors that can affect the productivity of universities, using data envelopment analysis and Cobb-Douglas type production functions. For instance, Adams and Griliches (1996) use a production function that relates the production of scientific articles with $R \& D$ expenditure and the number of scientists and engineers in the United States, according to their knowledge areas. Their results show a greater contribution to human capital in scientific production than contribution of investment in R\&D. 
Meng, $\mathrm{Hu}$, and Liu (2006) analyze China's case using the Cobb-Douglas model to investigate if factors such as investment in $R \& D$ and the number of researchers can explain the number of publications. Their results mention that the elasticity of investment in $R \& D$ is more relevant than the number of researchers in scientific productivity.

Erfanian and Ferreira (2017) used the Cobb-Douglas function to model scientific production using a balanced panel of thirty-one countries and nine years to estimate the elasticities of the financial resources used by researchers on their contributions in scientific production. The authors determine that both factors contribute in a similar way to the scientific production of the countries under study.

However, caution should be exercised in using the CobbDouglas model and the implicit assumptions of the model, which restrict the interpretation of the results obtained or their validity. For example, the assumption that units experience homogeneous production processes does not seem reasonable in scientific production due to the important differences between universities and their models of research management. These differences can also occur due to universities' specialization in different areas of knowledge and the time-specific dynamics of publication of knowledge areas.

In the classical model, there is no possibility of outsourcing some parts of the productive process. Part of the efficiency in the use of resources would imply considering the efficiency of other units. In the case of universities, this possibility exists due to national and international collaboration to generate scientific literature, which may influence a greater capacity to produce scientific texts from some universities concerning others.

Another assumption is related to the dynamics of the growth of the productive system and its scalability. The existence of constant returns to scale and diminishing returns of the marginal productivities of the factors generates the possibility of producing, regardless the size or quantity of available resources and the possibility of scaling production or substituting factors among themselves. However, there 
are limitations concerning the minimum endowments of resources to generate research in universities' case. Indeed, to the extent that these provisions increase, non-proportional increases in the units' productive capacity may occur, derived from the knowledge and experience accumulated in the publicity processes, where the larger units may have a greater capacity to generate scientific literature.

Finally, there may also be variations in the model's characterization parameters that are assumed to be constants. In the case of research systems, factors such as the generation of changes and innovations regarding how knowledge is created, the technological innovations that facilitate publication and dissemination, and the constant structural changes linked to quality in the system of higher education allows someone to assume that in practice these parameters can actually change over time.

The SFA solves some of the difficulties mentioned above because it is a method in which there are no a priori assumptions regarding the behavior of the productive process analyzed. Therefore, an SFA is carried out to determine the inefficiencies in the use of resources. It consists of a regression model in which the disturbance term consists of two different sources of errors; a random error and an inefficiency error that can be estimated for production and cost functions.

Since the publication of the seminal articles by Meeusen and Van den Broeck (1977) and Aigner, Lovell, and Schmidt (1977), this class of models has become a valuable tool for efficiency analysis (Lovell, 1995). An extensive review of these models can be found in Greene (2012) and the latest developments and updates in Lai, Hung-pin and Subal C. Kumbhakar (2018). However, few studies related to the analysis of scientific productivity that use this method are able to mention Agasisti's et al. (2016) and Chen's et al (2019).

Regarding the case study, the country's scientific productivity is explained almost entirely by the contribution made by higher education universities. In this case, the Chilean higher education system consists of 60 universities, of which 18 are public and 42 are 
private; however, only 47 universities present scientific production in the 2013-2017 period, with public participation taking precedence over private participation in terms of productivity. Besides, the system is characterized by the excessive concentration of production in three universities that represent $41 \%$ of the country's total annual scientific production and that are recognized as the traditional universities of the system ${ }^{4}$. A similar situation occurs with the distribution of financial resources and advanced human capital, which are concentrated in 34\% of the total existing system in these universities.

\section{Data and methodology}

For the analysis of scientific production, the information available in the National Council of Education of Chile (CNED) databases (available in https://www.cned.cl/indices) has been used to build a balanced panel of 49 Chilean universities for the period 2013-2017. This sample represents $85 \%$ of the total existing universities in the country and $100 \%$ of universities with scientific publications.

The data used to measure scientific productivity includes the number of scientific publications (P) indexed in Web of Science (WOS) that considers the collections SCI-EXPANDED, SSCI, A\&HCI, CPCI-S, and CPCI-SSH; the financial resources used for the operational functioning of these entities $(G)$; and the number of doctors hired in full-time universities (D).

In order to study the scientific production of universities in Chile, it is proposed to use a production function of the CobbDouglas type and the SFA. A theoretical summary of both methods is provided below. The models were estimated using Stata software.

The Cobb-Douglas model (Cobb \& Douglas, 1928; Douglas, 1976) relates the growth of scientific production explained by two independent variables, which are interpreted as productive factors,

4 In Chile, "traditional universities" are known as those that belong to the Council of Deans of Chilean Universities. There are both state and private and all of them were founded prior to 1981, or derive from others that used to be in this Council. 
plus three parameters that characterize the functioning of the productive process and their level of efficiency in the use of available resources, according to equation 1 :

$$
P_{i}=A_{i} G_{i}^{\alpha} D_{i}^{\beta} e^{u_{i}}
$$

In the equation, the dependent variable $P_{i}$ is the number of scientific articles generated in a year $t$ produced by university $i$; the independent variables are the operational expenses $G_{i}$ used by universities for their operation and the advanced human capital involved in productivity, measured by the number of academics in possession of the Doctorate degree $D_{i}$. $e^{u i}$ is a random component, it is considered a random error component of normal distribution. The parameters of characterization of the system are the total productivity of the factors $A_{i}$, henceforth TPF, which captures the degree of efficiency in the using resources and the constants $\alpha$ and $\beta$ that express the contribution of each factor in the total production.

The constants $\alpha$ and $\beta$ can be interpreted as the partial elasticities of the factors concerning scientific production (equations 4 and 5), so that if the sum of the constants equals 1 , the scientific production process experiences constant returns of scale, that is to say, an increase of $1 \%$ of the factors will imply an increase in the same percentage of the scientific production ${ }^{5}$. If the sum is greater or less than one, the increase in scientific production will be higher or lower than $1 \%$, respectively, regardless of the level of scientific production in which a particular university is located. The coefficients can also help estimate the substitution ratio that may exist between the factors to maintain the same level of production, as long as it is possible to do so. In this case, it can be shown that it is simply the division between the alpha and beta coefficients.

In the model, A explains the differences that may exist between universities in terms of the efficiency in the use of their available alpha and beta resources. These differences can be explained by various

5 In the model it can be shown that the growth rate of scientific production depends on a weighted sum of TFP growth rates and productive factors. 
factors such as economies of scale due to the size or efficiency of their resource management, technical progress, the quality of the human capital available, the accumulated experience, the collaboration networks to which they have access, the capacity to raise financial resources, among other factors.

This constant can be estimated empirically through the residual calculation method from equation (1) and is expressed as follows (R. E. Hall \& Jones, 1999) (see eq. 2)

$$
A_{i}=\frac{P_{i}}{G_{i}^{\alpha} D^{\beta}}
$$

The residual method has the advantage of using the directly observed data, assuming that the scientific production process is homogeneous among universities; which means that each university has the same $\alpha$ and $\beta$, which allows estimating the global productivity of each one in the sample.

The model parameters are estimated by the means of a regression model for longitudinal or panel data. However, before proceeding with a panel model's estimation, the appropriate model to be used must be defined between a linear model of fixed-effects and a model of random-effects.

In the fixed-effect model, from now on, FE, the panel-specific errors are treated as fixed parameters. These parameters are specific intercepts of the panel and allow the conditional mean of the dependent variable to vary between the panels. The linear estimator of fixed-effects is consistent, even if the regressors are correlated with the fixed-effects. In contrast, a random-effects model for panel data, after this RE, treats panel-specific errors as uncorrelated random variables drawn from a population with zero mean and constant variance. The regressors should not be correlated with the randomeffects so that the estimates are consistent.

The Hausman test (1978) is used to determine the appropriate model, which defines a null hypothesis that the random-effects model is the correct one to use, versus a model with fixed-effects as the 
alternative hypothesis (Greene, 2008, chapter 9). The test consists of determining if the unique errors $\left(\mu_{\mathrm{i}}\right)$ are correlated with the regressors, while the null hypothesis states that they are not ${ }^{6}$.

Once defined that a model of fixed-effects will be used, the Cobb-Douglas function is converted to a linear model by applying logarithms to equation (1), obtaining an expression suitable for econometric estimation, as follows (see eq. 3 )

$$
\ln \left(P_{i t}\right)=\beta_{0}+\alpha \ln \left(G_{i t}\right)+\beta \ln \left(D_{i t}\right)+\mu_{i}+\delta_{t}+\varepsilon_{i t}
$$

In the econometric model, $\mu_{i}$ is the fixed-effect that captures heterogeneity among universities and does not vary over time, $\delta_{t}$ is the fixed-effect over time that captures the changes that can occur in the system caused by shocks or external events in a determined moment, while $\varepsilon_{i t}$ is the random disturbance. In this case, the fixedeffect model allows controlling the institutional differences between universities and structural changes that can occur over time, and that may similarly affect all universities in a similar way.

The SFA model is motivated by the theoretical idea that the units analyzed may be contained in a maximum possible efficiency frontier, on which some of them may or may not be, and that any deviation from this frontier represents individual deficiencies. From the statistical point of view, this idea is implemented by specifying a regression model characterized by a compound error term that includes the classical idiosyncratic classical term of disturbance and the disturbance or error represented by inefficiency. Regardless of whether it is sectional or panel data, production or cost frontier, variable or invariable inefficiency, SFA parametric models are generally estimated by methods based on maximum likelihood (ML) probability.

6 It is relevant to note that another important assumption of the FE model is that these invariable characteristics over time are unique to the individual and should not be correlated with other individual characteristics. Each entity is different, therefore, the error term of the entity and the constant that captures the individual characteristics should not be correlated with each other. Now, if the error terms are correlated, then the EF is not the appropriate model since the inferences may not be correct and, therefore, you need to model that relationship using a random-effects model (RE), this is the main reason behind the Hausman test. 
The SFA model assumes that each company produces potentially less than it could because of some degree of inefficiency. Specifically, a production function of the type eq. 4 ,

$$
q_{i}=f\left(z_{i}, \beta\right) \varepsilon_{i}
$$

where $\varepsilon_{i}$ is the level of efficiency for the company and that must necessarily be in the interval $(0,1)$. If $\varepsilon_{i}$ is equal to 1 , the company is achieving the optimum result with the technology incorporated in the production function $f\left(z_{i}, \beta\right)$. When $\varepsilon_{i}<1$, the company is not taking full advantage of the $z_{i}$ inputs given the technology incorporated in the production function $f\left(z_{i}, \beta\right)$. Due to the assumption that the output is strictly positive (i.e., $q_{i}>0$ ), it is assumed that the degree of technical efficiency is strictly positive (i.e., $\varepsilon_{i}>0$ ). It is also assumed that the output is subject to random shocks, which implies that

$$
q_{i}=f\left(z_{i}, \beta\right) \varepsilon_{i} \exp \left(v_{i}\right)
$$

Taking the natural logarithm of both sides

$$
\ln \left(q_{i}\right)=\ln \left(f\left(z_{i}, \beta\right)\right)+\ln \left(\varepsilon_{i}\right)+v_{i}
$$

Assuming that there are $k$ entries and that the production function is linear in logarithms, defining $u_{i}=-\ln \left(\varepsilon_{i}\right)$, one has to

$$
\ln \left(q_{i}\right)=\beta_{0}+\sum_{j=1}^{k} \beta_{j} \ln \left(z_{j i}\right)+v_{i}-u_{i}
$$

Because $u_{i}$ is subtracted from $\ln \left(q_{i}\right)$, restricting $u_{i} \geq 0$ implies that $0<\varepsilon_{i} \leq 1$, as specified above.

\section{Results}

The main descriptive statistics of the data used in this analysis are shown in Table 1 . The main variables to be analyzed are the number of scientific published articles, the number of financial resources allocated to the operational expenses of scientific production (MMChilean Pesos), and the number of academics or researchers holding a doctoral degree. 
Table 1.

Panel data statistical summary (2013-2017)

\begin{tabular}{|c|c|c|c|c|c|c|}
\hline Variables & Mean & St. Dev. & Min. & Max. & Asymmetry & AGR \\
\hline $\begin{array}{l}\text { Scientific } \\
\text { Publications } \\
\text { (number of papers) }\end{array}$ & 240.4 & 436.1 & 1.0 & 2584 & 3.6 & 30.7 \\
\hline $\begin{array}{l}\text { Operational } \\
\text { Expenses (MM\$ } \\
\text { Chilean pesos) }\end{array}$ & 59.9 & 83.7 & 1.3 & 501 & 3.5 & 7.1 \\
\hline $\begin{array}{l}\text { Researchers (Ph.D., } \\
\text { number of persons) }\end{array}$ & 140.3 & 204.6 & 0.0 & 1063 & 2.7 & 9.6 \\
\hline
\end{tabular}

Source: CNED and the Ministry of Education of Chile. AGR: Average Growth Rate.

From the data, it can be seen that there is great heterogeneity among universities regarding their levels of scientific articles, which generates their operational expenses and available human capital. Additionally, the data shows great asymmetry and dispersion. This situation reflects the important differences that exist among universities that lead the scientific production process and the rest of the sample.

It is possible to see that universities have experienced significant growth in their factors, particularly the volume of scientific articles and the number of doctors hired (AGR column). This reflects the sustained growth of scientific productivity in recent years, although with certain nuances, given the differences among institutions (view fig. 1).

Figure 1.

Aggregate behavior of the variables analyzed universities in the period 2013-2017.

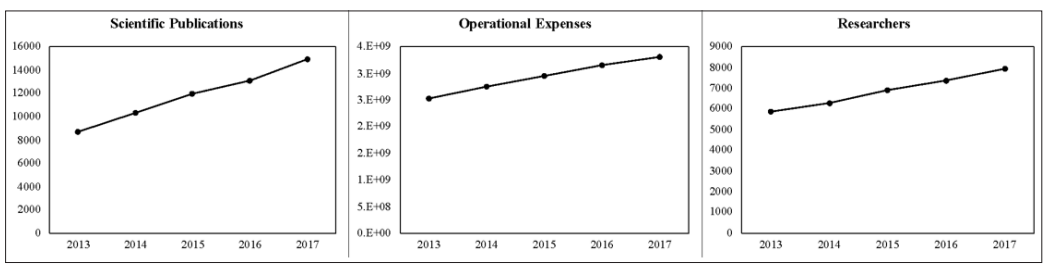

Source: Authors' elaboration.

The Cobb-Douglas estimates are shown in Table 2, considering three different models; a simple linear multivariate model (1); a panel 
data model with fixed-effects between universities (2); and a third model that combines fixed-effects between universities with fixedeffects over time (3).

Table 2 .

Cobb-Douglas estimated models

\begin{tabular}{cccc}
\hline \multirow{2}{*}{ Parameters } & OLS & \multicolumn{2}{c}{ Fixed-effects } \\
\cline { 2 - 4 } Constant & $(1)$ & $-16.550^{* * *}$ & -6.826 \\
& $-7.918^{* * *}$ & $(3.709)$ & $(5.142)$ \\
$\alpha$ & $(1.068)$ & $1.086^{* * *}$ & 0.541 \\
& $0.513^{* * *}$ & $(0.217)$ & $(0.295)$ \\
$\beta$ & $(0.068)$ & $0.467^{* * *}$ & $0.452^{* * *}$ \\
& $0.805^{* * *}$ & $(0.056)$ & $(0.056)$ \\
$\delta_{2014}$ & $(0.042)$ & & $-0.370^{* *}$ \\
& & & $(0.113)$ \\
$\delta_{2015}$ & & & $-0.218^{* *}$ \\
& & & $(0.101)$ \\
$\delta_{2016}$ & & & $-0.223^{* *}$ \\
& & & $(0.902)$ \\
$\delta_{2017}$ & & & $-0.219^{* *}$ \\
& & & $(0.085)$ \\
Observations & 145 & 0.83 & 145 \\
Number of groups & - & - & 0.87 \\
$\mathrm{R}^{2}$ & 0.87 & & - \\
$\mathrm{R}^{2}$-adjusted & 0.87 & & \\
\hline
\end{tabular}

Note: Standard error in parentheses. * Significance $\mathrm{p}<0.05, * *$ Significance $\mathrm{p}<0.01$, $* * *$ Significance $\mathrm{p}<0.001$. (1) Simple multiple linear regression, (2) regression from fixed-effects panel between units (3) regression fixed-effects between units and time.

From Table 2, it is discernible that all the models have a high explanatory power regarding the differences in scientific production between universities. Furthermore, it can be observed that the parameters of the model are positive. Therefore, the factors operating expenses $(G)$ and the number of doctors $(D)$ influence the growth of the scientific production of the universities. Since the estimated value of the Chi-square test is 4.91, with a p-value of 0.027 , the null hypothesis is rejected and, therefore, the fixed-effect model (FE) must be used. Due to the logarithmic transformation, the parameters of 
the model are interpreted as elasticities. Consequently, the elasticity linked to the operational expenses $G$ presents a higher value (1.086) concerning the factor linked to the number of doctors $D(0.467)$. Therefore, operating expenses have a greater impact on the scientific production of Chilean universities.

From the results, it should be mentioned that there are differences in the elasticities. In the case of the simple OLS model (1), there are problems of non-normality of the residue due to the important heterogeneity between the units. The model of the fixedeffects panel model between units and time (3) is a homoscedastic model without serial autocorrelation, but the operational expenses factor has no statistical significance. A different situation occurs with the fixed-effects model (2) which does not consider a fixed-effect over time. It is a homoscedastic model free of autocorrelation with significant parameters at the level of 0.001 , and consequently the model that best interprets the production function.

The coefficients, being positive and significant, imply that both factors are relevant in explaining the scientific production of the universities; results that coincide with previous studies, which associate a positive impact of the stock of financial capital and human capital in scientific production processes (Adams \& Griliches, 1996; Hall et al., 2010).

Similarly, the parameter specifically linked to operational expenses being greater than that linked to human capital implies that it has a greater impact on the growth of scientific production in universities. These results are similar to those presented by Mueller (2016), which determines financial resources as a factor of greater scientific production incidence. In contrast, the parameters determined in studies at the country level carried out by Erfanian and Ferreira (2017) determine that the number of researchers and their quality has a greater effect on academic scientific productivity than financial or operational resources.

The sum of the elasticities obtained from model (2) is greater than $1(\alpha+\beta=1.55)$, which indicates that the scientific production 
process is experiencing an increase in returns at scale. This implies that an increase of $1 \%$ in both factors generates a direct increase of $1.55 \%$ in the scientific production of universities. The rejection of the null hypothesis of constant returns of scale with a level of significance of $1 \%$ also confirms the presence of increasing returns at scale.

On the other hand, the substitution ratio between factors is 2.33, indicating that it is elastic and that replacing financial capital with human capital is feasible. In this context, it may be part of the initial strategy of universities with low scientific productivity which first start to attract doctoral degree academics. However, the model shows that the resources captured by universities are relevant. This is because universities can allocate resources to improve their research environments, and even allocate economic resources to stimulate the productivity of their researchers.

Considering the correlation between TFP and average productivity ratio, Figure 2 shows the individual measurement of the TFP of each university, estimating its value by the residual method, where it is assumed that all universities have the same values in their parameters $\alpha$ and $\beta$. Another assumption of this approach is that the process of scientific production is homogeneous among universities. The differences between two entities, with the same endowment of factors, are due to the efficiency in the use of available resources. 
Figure 2.

Correlation between Average Productivity Ratio (APR) and Total Factor Productivity of universities (TFP).

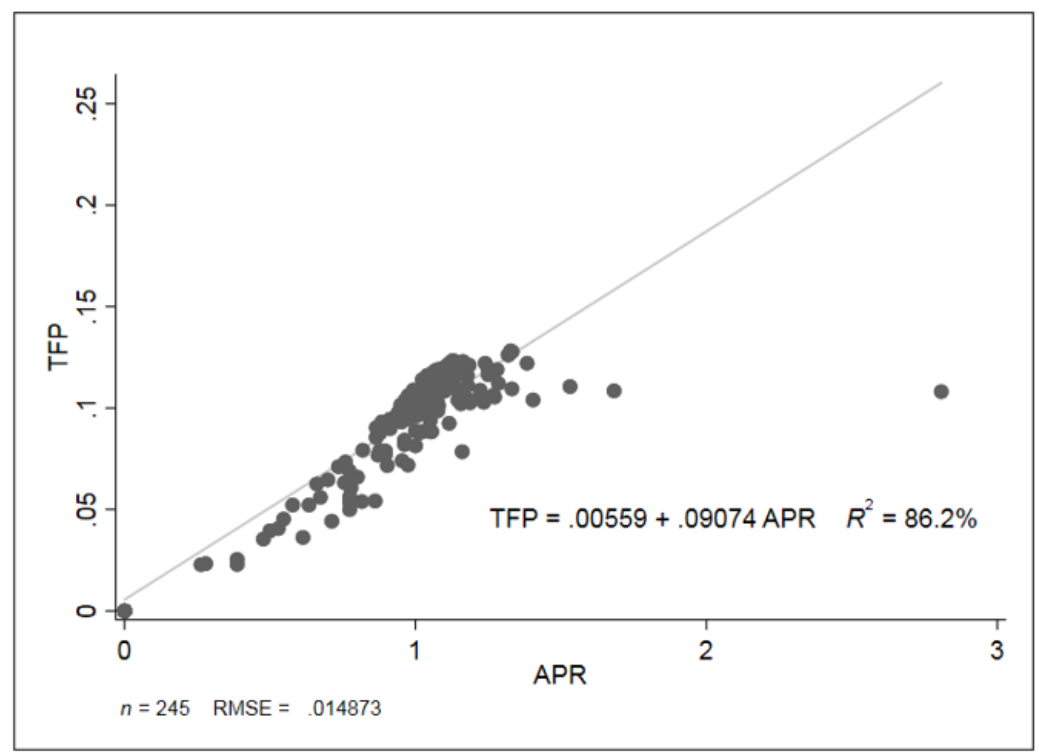

Source: Authors' elaboration.

In Figure 2, it can be observed that there is a positive correlation between average productivity, defined as the ratio between the number of papers and the number of doctors and A (the Total Factor Productivity, TFP). The high and positive correlation between these two variables reflects the close relationship between efficiency and economies of scale. In this sense, it can be stated that there are minimums necessary for the productivity of a university to increase. From that minimum value, universities through their organization, allocation of resources and development of a favorable environment can present higher levels of scientific productivity than others. In this sense, those public policies that make it easier for universities with low scientific productivity to achieve these minimums will not only impact the targeted university, but will also stimulate systemwide productivity because of the extensive scope for improvement that these universities can present. Regarding the SFA model, Table 3 summarizes its estimates as follows, 
Table 3.

Result of estimation Stochastic Frontier model.

\begin{tabular}{cc}
\hline Parameter & Stochastic \\
\hline Constant & -16.550 \\
$\alpha$ & $(3.709)$ \\
& 1.086 \\
$\beta$ & $(0.217)$ \\
& 0.467 \\
$\sigma_{u}$ & $(0.056)$ \\
$\sigma_{v}$ & 0.771 \\
$\sigma^{2}$ & 0.424 \\
$\lambda$ & 0.774 \\
\hline
\end{tabular}

Source: Authors' computations.

The SFA model estimates the standard deviation of both error components ( $u$ and $v$ ). The s.d. of the inefficiency error $\sigma_{u}$ being greater than the s.d. of the idiosyncratic error $\sigma_{v}$. The total variance of the error is 0.774 . The estimate of the relationship between the s.d. of the inefficiency component and the s.d. of the characteristic lambda component is 1.82 . The final value indicates that for the Chilean universities, the s.d. of the technical inefficiency component is 1.82 times greater than the characteristic error component. The likelihood ratio test (LR Test) derived from the model also indicates that the null hypothesis is rejected if the variance of the inefficiency component is equal to zero, in contrast to the alternative hypothesis that the variance of the inefficiency component is greater than zero $H_{0}: \sigma_{u}^{2}=0, H_{A}: \sigma_{u}^{2}>0$, LR Test of $\sigma_{u}^{2}=0 \Rightarrow \chi^{2}=0.00$.

With a level of significance of $1 \%$, the result of the likelihood ratio test confirms the importance of the inefficiency component in the use of research resources at Chilean universities.

The model also estimates that, on average, the technical efficiency for the sample of 49 universities is $78.1 \%$. In other words, there is a $21.9 \%$ inefficiency in the research system of Chilean universities. According to the SFA model, table 4 shows the values of technical efficiency for the first four most efficient Chilean institutions. 
Table 4.

Most efficient universities

\begin{tabular}{clc}
\hline Ranking & \multicolumn{1}{c}{ University } & Efficiency $^{*}$ \\
\hline 1 & Pontificia Universidad Católica de Chile & 0.98 \\
2 & Universidad de Chile & 0.97 \\
3 & Universidad de Valparaíso & 0.95 \\
4 & Universidad Austral de Chile & 0.95 \\
\hline
\end{tabular}

*Values close to 1 denote greater efficiency. Source: Authors' computations.

As a counterpart, and according to the data, $49 \%$ of Chilean universities are under the average efficiency of $78.1 \%$. In other words, 24 of the 49 institutions of higher education in the sample have inefficiencies in the use of their resources, that is, despite the scarcity of resources, both human capital and financial and operational resources, Chilean universities do not use their current research resources efficiently. Figure 3 shows the efficiency of the 49 analyzed institutions.

Figure 3.

Efficiency at Chilean universities

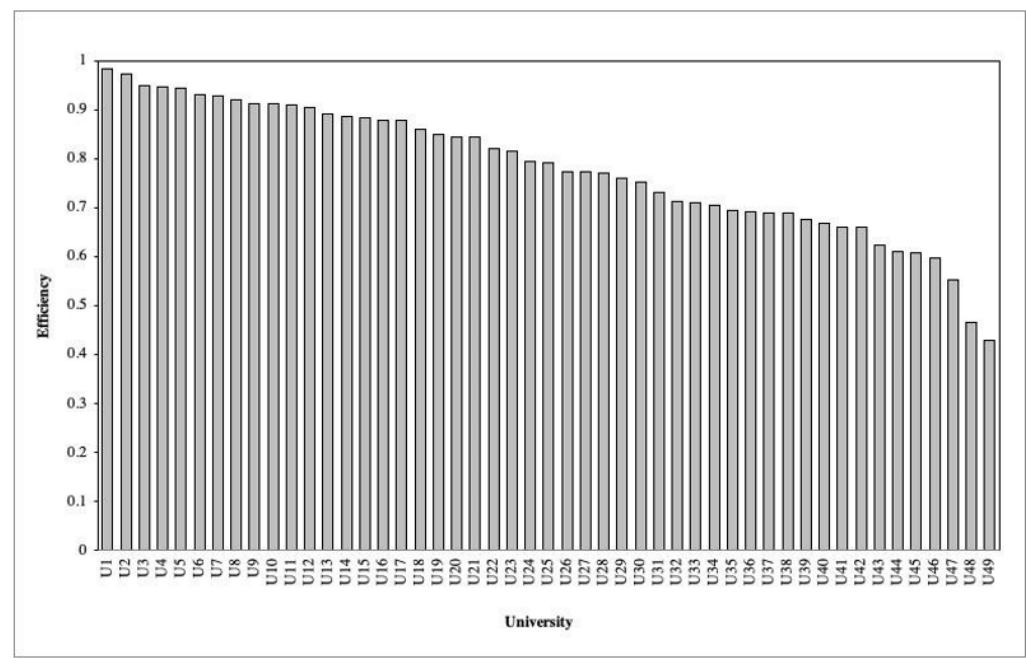

Source: Authors' elaboration. 


\section{Discussion}

Based on both methods, the residual estimation of productivity (Cobb-Douglas model) and the efficient frontier estimate (SFA), it is possible to explain the gaps in scientific publications among the various educational institutions, regardless of the level of their productive inputs. In this aspect, both the value of the A or Total Factor Productivity and the value of Technical Efficiency are tangible and comparable expressions of the heterogeneous capacity that the universities have with regard to the efficient use of their resources.

Regarding the differences and complementarities of the models, it can be mentioned that in this case, the estimated coefficients are coincident concerning the sign and impact of the factors considered in the scientific production of the universities. Despite the differences regarding the methodologies, it can be seen that the estimates are identical. Therefore, it can be assumed that for the case of the scientific productivity of the Chilean universities both models are valid to determine the degree of efficiency in the scientific production.

Additionally, it should be considered that the Cobb-Douglas model in its simplest form assumes constant returns of scale, though; increasing returns to scale are identified for the Chilean case, which implies that the size of the units and their ability to produce scientific texts is a determining factor. The SFA model allows estimating a potential production boundary and the degree of inefficiency of each of the units, which can quantify the degree of inefficiency presented by the most productive universities in the system. It is interesting to note that both models do not determine if the degree of inefficiency comes from the unit's technical level or if it is due to the efficiency of the methods used for scientific production. In this case, technical progress is related to universities having the minimum resources to research and disseminate examination results and have human capital with the skills and knowledge to produce scientific texts.

Both approaches have made it possible to estimate the alpha and beta coefficients, and to approximate the contribution of the variables to scientific productivity. This information is relevant, 
because it has been determined that both the human capital factor and the financial resources factor are relevant to explain the scientific productivity of Chilean universities.

Besides, it has been determined that in the Chilean case the economic factor is more relevant in the productivity of the universities. Despite the fact that substitution between the variables is feasible, we assume that it is only on a small scale; In other words, the smaller universities and those with the lowest scientific productivity may be a strategy to favor the hiring of academics with a doctorate degree to improve scientific productivity; But as their scientific productivity improves, more financial resources will inevitably be required to provide funding for teaching and research activities.

The results are important from the perspective of public policies that promote scientific productivity. Policy must consider that both advanced human capital and financial resources are important factors affecting scientific production. In addition, it should be considered that advanced human capital plays a relevant role in scientific productivity and that the allocation of resources for its insertion can have a significant impact on those universities that present low levels of productivity. But then economies of scale play an important role in maintaining and perpetuating the existing gaps between universities, where universities are more productive because they have a greater endowment of resources.

The SFA analysis has shown that there are important differences regarding the efficiency in the use of the resources available to universities, and therefore space to improve the management of the resources used for research. In this sense, those policies that encourage better research management and improve research environments can have a high influence on the productivity of the Chilean research system. Furthermore, it has been determined that the universities with the best performances are not exclusively the largest ones. They are not located in the capital of the country, but there are also regional universities that have reached levels of efficiency similar to the most important traditional ones; This may be due to different factors such as better management models, resource allocation or 
research facilities; Therefore, new studies are required to elucidate what factors may be promoting greater efficiency in these universities.

If it is desired to reverse this imbalance in the research system, progress must be made in changing the current financing model, which favors universities that have more qualified personnel and a greater number of financial resources, towards one that is more supportive, decentralized and able to develop a more balanced system.

Resources should also be considered to improve the efficiency of universities, which can be used, for example, to improve their processes of research and scientific dissemination, or for the development of a favorable environment to scientific production, or to access networks of research, or to reduce the teaching load and administrative activities, so that teachers could dedicate more time to research activities, among other possible actions. If the aim is to achieve a balanced development of the research system and improve the scientific productivity of the country, any action or initiative that allows taking a step forward will be beneficial.

\section{Conclusions}

This research analyzes Chilean universities' scientific production for the period 2013-2017 using a balanced data panel and two approaches estimating the productivity of universities; a growth model that considers an aggregate production function of the CobbDouglas type and a Stochastic Frontier Analysis (SFA).

The main findings show a high correspondence of the model with scientific productivity presented by universities, where productivity plays a relevant role, which partly explains the different efficiencies presented by universities in the use of their human and financial resources. The Cobb-Douglas model shows the Chilean university system experiences increasing returns to scale; this implies that those policies that facilitate the capture of financial resources and increase of advanced human capital by universities, particularly 
those that are less productive, can have a significant impact on the country's scientific production.

The SFA model showed that there are important differences in efficiency between universities, where the most productive ones show efficiency levels close to $100 \%$ and others with levels lower than $70 \%$, which shows important gaps that should be corrected in the Chilean science and technology system.

These results are relevant, because an excellent dynamic model allows the follow-up and monitoring of public investment, recruitment programs by High Education Institutions-HEI. Finally giving space to the adaptation of public policies to Science and Technology. In particular, policies that can help reverse the gap between the most productive universities and the others, and thus achieve a more balanced system.

It should be mentioned that like all research work, this one has weaknesses that must be considered when generalizing its results; first, the Ph.D. degree variable, although critical, is not the only variable that should be considered in human capital in HEIs. It is essential to mention that according to the HEI, there are several sources of academic, professional, and personal research that contribute to productivity. Still, they do not always appear in the institutional databases. In this regard, our model does not consider the role of students, highly productive medical specialties, doctoral programs, external competitive funds, postdoctoral programs. Surely this would enrich any explanatory model of growth of scientific productivity. In addition, there are other elements that must be considered in terms of the scientific productivity of universities and that can explain to some extent the existing gap between universities; for example, the social capital existing within the researchers' networks, when there are collaborative networks, knowledge management processes become more efficient, especially in these terms, where obtaining a scientific publication presents a good part of science, but also a part of technique and skills that are not part of the registry, but rather of the repertoire. For this reason, research is required that delves into these elements for a better understanding 
of the productivity achieved by some universities that present better performance than others.

Future works can deepen into those institutional factors that can affect the productivity of the universities. They can go into those aspects that have a relation with the configuration of the human capital and the effectiveness of the competitive funds of investigation for the development of scientific productivity. It may also be of interest to determine the factors that affect the quality of scientific publications in Chile. It may be a factor that explains the low productivity presented by some universities.

\section{Acknowledgments}

We would like to thank the anonymous reviewers whose comments contributed significantly to improving the article.

\section{References}

Acemoglu, D. (2012). Introduction to economic growth. Journal of Economic Theory, 147(2), 545-550. https://doi.org/10.1016/J.JET.2012.01.023

Adams, J., \& Griliches, Z. (1996). Measuring science: an exploration. Proceedings of the National Academy of Sciences of the United States of America, 93(23), 12664-12670. https://doi.org/10.1073/ PNAS.93.23.12664

Aigner, D. J., C. A. K. Lovell, \& P. Schmidt (1977). Formulation and estimation of stochastic frontier production function models. Journal of Econometrics 6: 21-37.

Agasisti T, Barra C, Zotti R (2016). Evaluating the efficiency of Italian public universities (2008-2011) in presence of (unobserved) heterogeneity. Soc Econ Plann Sci (55). 47-58.

Barro, R. J. (1990). Human capital and growth: Theory and evidence. A comment. Carnegie-Rochester Confer. Series on Public Policy. https:// doi.org/10.1016/0167-2231(90)90029-K

Barro, R. J. (2001). Human Capital and Growth. American Economic Review, 91(2), 12-17. https://doi.org/10.1257/aer.91.2.12

Castro-Ceacero, D., \& Ion, G. (2018). Changes in the University Research Approach: Challenges for Academics' Scientific Productivity. Higher Education Policy, 1-19. https://doi.org/10.1057/s41307-018-0101-0 
Cobb, C. W., \& Douglas, P. H. (1928). A Theory of Production. American Economic Association. https://doi.org/10.1515/humr.1998.11.2.161

Douglas, P. H. (1976). The Cobb-Douglas Production Function Once Again: Its History, Its Testing, and Some New Empirical Values. Journal of Political Economy, 84(5), 903-915. https://doi.org/10.1086/260489

Erfanian, E., \& B. Ferreira Neto, A. (2017). Scientific output: labor or capital intensive? An analysis for selected countries. Scientometrics, 112(1), 461-482. https://doi.org/10.1007/s11192-017-2369-z

Fernandez-Cano, A., Torralbo, M., \& Vallejo, M. (2004). Reconsidering Price's model of scientific growth: an overview. Scientometrics. Retrieved from http://www.akademiai.com/doi/abs/10.1023/ B\%3ASCIE.0000045112.11562.11

Hausman, J. A. (1978). Specification tests in econometrics. Econometrica 46: 1251-1271.

Gemmell, N. (2010). Evaluating the Impacts of Human Capital Stocks and Accumulation on Economic Growth: Some New Evidence†. Oxford Bulletin of Economics and Statistics. https://doi. org/10.1111/j.1468-0084.1996.mp58001002.x

Greene, William H. (2008). Econometric analysis 6th ed., Upper Saddle River, N.J.: Prentice Hall, 2008.

Greene, William H. (2012). Econometric Analysis. 7th ed. Upper Saddle River, NJ: Prentice Hall.

Hall, B. H., Mairesse, J., \& Mohnen, P. (2010). Measuring the returns to RandD. In Handbook of the Economics of Innovation. https://doi. org/10.1016/S0169-7218(10)02008-3

Hall, R. E., \& Jones, C. I. (1999). Why Do Some Countries Produce So Much More Output Per Worker than Others? The Quarterly Journal of Economics, 114(1), 83-116. https://doi.org/10.1162/003355399555954

Lai H.-P., \& Kumbhakar, S.C. (2018). Panel data stochastic frontier model with determinants of persistent and transient inefficiency. European Journal of Operational Research, 271, (2), 746-755

Lovell, C.A. (1995), Econometric efficiency analysis: A policy-oriented review. European Journal of Operational Research, 80, 452-461.

Meng, W., Hu, Z., \& Liu, W. (2006). Efficiency evaluation of basic research in China. Scientometrics, 69(1), 85-101. https://doi.org/10.1007/s11192006-0140-y

Meeusen, W., \& Van den Broeck, J. (1977). Efficiency estimation from CobbDouglas production functions with composed error. International Economic Review 18: 435-444. 
Mueller, C. E. (2016). Accurate forecast of countries' research output by macro-level indicators. Scientometrics, 109(2), 1307-1328. https:// doi.org/10.1007/s11192-016-2084-1

National Council of Education of Chile (CNED, https://www.cned.cl/indices)

Scott, J. C. (2006). The Mission of the University: Medieval to Postmodern Transformations. The Journal of Higher Education. https://doi. org/10.1353/jhe.2006.0007

Solarin, S. A., \& Yen, Y. Y. (2016). A global analysis of the impact of research output on economic growth. Scientometrics, 108(2), 855-874. https:// doi.org/10.1007/s11192-016-2002-6

Wong, C.-Y. (2019). A century of scientific publication: towards a theorization of growth behavior and research-orientation. Scientometrics, 1-21. https://doi.org/10.1007/s11192-019-03048-5

Recibido: 27/10/2020

Aceptado: 05/05/2021 


\section{Appendix}

Table 5.

List of universities considered in the study.

\begin{tabular}{ll}
\hline Cod. & \\
\hline U1 & PONTIFICIA U. CATÓLICA DE CHILE \\
U2 & U. DE CHILE \\
U3 & U. DE VALPARAISO \\
U5 & U. AUSTRAL DE CHILE \\
U6 & U. DEL BIO BIO \\
U7 & U. DE TALCA \\
U8 & U. DE LA FRONTERA \\
U9 & U. CATOLICA DEL NORTE \\
U10 & U. CATOLICA DE LA SANTÍSIMA CONCEPCIÓN \\
U11 & U. DE CONCEPCIÓN \\
U12 & U. DE SANTIAGO DE CHILE \\
U13 & U. ARTURO PRAT \\
U14 & U. DIEGO PORTALES \\
U15 & U. DE TARAPACÁ \\
U16 & U. ANDRES BELLO \\
U17 & U. DE LOS LAGOS UNIACC \\
U18 & U. TÉCNICA FEDERICO SANTA MARÍA \\
U19 & U. DE LA SERENA \\
U20 & U. CATÓLICA DEL MAULE \\
U21 & U. FINIS TERRAE \\
U22 & U. CHILENO BRITÁNICO DE CULTURA \\
U23 & U. ALBERTO HURTADO \\
U24 & U. SANTO TOMÁS \\
U25 & U. DE ANTOFAGASTA \\
U26 & U. ACADEMIA DE HUMANISMO CRISTIANO \\
U27 & U. BERNARDO O'HIGGINS \\
U28 & PONTIFICIA U. CATÓLICA DE VALPARAÍSO \\
U29 & U. DE PLAYA ANCHA DE CIENCIAS DE LA EDUCACIÓN \\
U30 & U. CATÓLICA DE TEMUCO \\
U31 & U. DEL DESARROLLO \\
U32 & U. SAN SEBASTIÁN \\
U33 & U. GABRIELA MISTRAL \\
U34 & U. METROPOLITANA DE CIENCIAS DE LA EDUCACIÓN \\
U. CENTRAL DE CHILE \\
U. ADOLFO IBÁNEEZ \\
U. AUTONOMÍA DE CHILE \\
UnA DELANES
\end{tabular}


270 ANALYSIS OF THE SCIENTIFIC PRODUCTIVITY AND TECHNICAL EFFICIENCY OF CHILEAN UNIVERSITIES - C. Colther, P. Piffaut, A. Montecinos
U41 U. DE ATACAMA
U42 U. BOLIVARIANA
U43 U. DEL PACÍFICO
U44 U. MAYOR
U45 U. LA REPÚBLICA
U46 U. CATÓLICA CARDENAL RAÚL SILVA HENRÍQUEZ
U47 U. PEDRO DE VALDIVIA
U48 U. ADVENTISTA DE CHILE
U49 U. DE LAS AMÉRICAS 